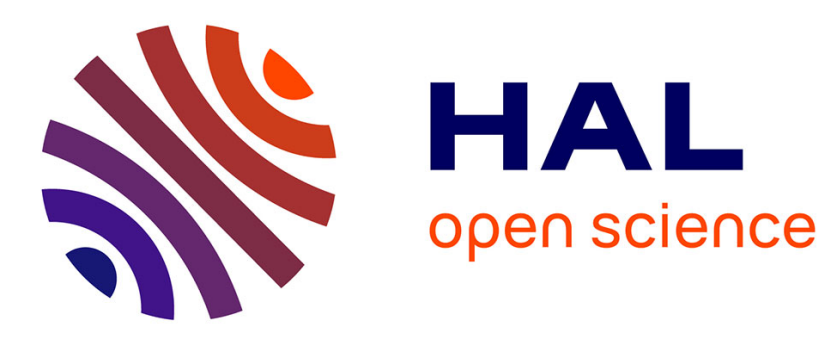

\title{
Optimized Beaconless Geo-Routing for Smart Utility Networks
}

\author{
Ahmed Bader, Karim Abed-Meraim, Mohamed-Slim Alouini
}

\section{To cite this version:}

Ahmed Bader, Karim Abed-Meraim, Mohamed-Slim Alouini. Optimized Beaconless Geo-Routing for Smart Utility Networks. IEEE Sensors Journal, 2013, 13 (12), pp.IEEE SENSORS JOURNAL, VOL.13, NO.12, DECEMBER 2013. hal-01002354

\section{HAL Id: hal-01002354 https://hal.science/hal-01002354}

Submitted on 13 Jan 2015

HAL is a multi-disciplinary open access archive for the deposit and dissemination of scientific research documents, whether they are published or not. The documents may come from teaching and research institutions in France or abroad, or from public or private research centers.
L'archive ouverte pluridisciplinaire HAL, est destinée au dépôt et à la diffusion de documents scientifiques de niveau recherche, publiés ou non, émanant des établissements d'enseignement et de recherche français ou étrangers, des laboratoires publics ou privés. 


\title{
Optimized Beaconless Geo-Routing for Smart Utility Networks
}

\author{
Ahmed Bader, Karim Abed-Meraim, Senior Member, IEEE, and Mohamed-Slim Alouini, Fellow, IEEE
}

\begin{abstract}
In this letter, we propose to employ beaconless geo-routing in conjunction with the recently ratified IEEE 802.15.4g physical layer standard for smart utility networks. We devise a simple yet an optimized mechanism for selecting the best candidate relaying node. We then compare the end-to-end energy performance of the optimized protocol with the routing protocol for low power and lossy networks (RPL); an IETF standardized specification. We demonstrate that the optimized protocol outperforms RPL particularly when the smart meters are situated more than one hop away from the sink.
\end{abstract}

Index Terms-Geographical routing, smart utility networks, OFDM.

\section{INTRODUCTION}

$\mathbf{T}$ HE IEEE 802.15.4g-2012 standard was ratified in 2012. It comes as an amendment to the IEEE 802.15.4-2011 standard to address the needs for outdoor low-data-rate Smart Utility Network (SUN) [1]. Two alternate physical layer (PHY) options were defined, one of which utilizes a multi-rate orthogonal frequency division multiplexing and is dubbed MR-OFDM. Although the work at the PHY level has been already completed, there is still a need however to complement the $802.15 .4 \mathrm{~g}$ standard with a multihop routing mechanism. To that end, several efforts are taking place including the Routing Protocol for Low Power and Lossy Networks (RPL) [2] which was published by the Internet Engineering Task Force (IETF) in 2012. Several academic and industrial entities have participated in authoring this protocol specification.

In this letter, we advocate the use of beaconless multihop geo-routing in conjunction with the 802.15.4g standard. Beaconless geo-routing protocols have indeed emerged as some of the most efficient routing techniques for wireless sensor networks (WSN) [3]. In beaconless geo-routing, candidate relaying nodes contend for forwarding the packet. The sender first issues a Request-To-Send (RTS) message. Candidate relaying nodes get ready to respond with a Clear-ToSend (CTS) message. However, each node weighs its response time according to a desired mix of forwarding attributes (e.g. closeness to destination, residual battery energy, ...). The node with the most favorable attributes should typically

Manuscript received July 11, 2013; accepted September 12, 2013. Date of publication September 18, 2013; date of current version October 4, 2013. This work was supported by a grant from King Abdulaziz City of Science and Technology. The associate editor coordinating the review of this paper and approving it for publication was Prof. Kiseon Kim.

The authors are with the King Abdulaziz City of Science and Technology, Strategic Research Initiative on Uncertainty Quantification in Sciences and Engineering, Riyadh 11442, Saudi Arabia (e-mail: bader@ telecom-paristech.fr; karim.abed-meraim@univorleans.fr; slim.alouini@ kaust.edu.sa).

Color versions of one or more of the figures in this letter are available online at http://ieeexplore.ieee.org.

Digital Object Identifier 10.1109/JSEN.2013.2282468 win the contest. Beaconless geo-routing is almost indifferent to topological changes in the networks that may be caused by node failure, battery depletion, or application of random sleeping schedules.

In this letter, we actually introduce a simple yet optimized mechanism for relay selection in beaconless geo-routing protocols. As a result we gain significant performance enhancements particularly in terms of energy efficiency over the IETF-RPL protocol.

\section{Optimized Beaconless GeO-Routing}

The optimized geo-routing scheme proposed in this letter makes use of the underlying OFDM PHY of the 802.15.4g specification to achieve the minimum forwarding delay. Our proposed scheme. The main contribution is in the design of the CTS message. The idea here is to shift the contention process from the time domain to the frequency domain. One whole OFDM symbol composed of an ensemble of $v$ subcarriers is allocated specifically for this purpose. The IEEE $802.15 .4 \mathrm{~g}$ standard specifies 4 values for $v$ (equivalent to the sixe of the FFT block): 16, 32, 64, and 128. The optimized relay selection process operates as follows (and is further illustrated in Figure 1):

1) The sender issues a RTS message, which - at minimum includes the position information of the sender and the destination. As illustrated in Figure 1, nodes may fall in the positive progress area (PPA) or the negative progress area (NPA). Those in the PPA will become candidate relaying nodes.

2) Each candidate relaying node compares its position to those of the sender and the destination. Accordingly, it determines in which forwarding zone it falls.

3) Each candidate relaying node is required to modulate one of the $v$ subcarriers allocated in the CTS message. The larger the progress a node offers towards the destination, the higher the subcarrier index it will select to modulate. Each node makes its subcarrier selection decision locally, i.e. without reverting to any sort of coordination with other candidate relaying nodes.

4) Candidate relaying nodes concurrently transmit the CTS composite frame as illustrated in Figure 1.

5) The sender performs non-coherent energy detection on the output of the FFT block of that allocated OFDM symbol to detect which subcarriers have been energized. A decision threshold is used on each subcarrier output to judge whether this subcarrier contains only noise or has been actually illuminated by one of the candidate relaying nodes.

6) The sender then transmits the data packet and uses a specific field to indicate the highest subcarrier index noted in the previous step. 


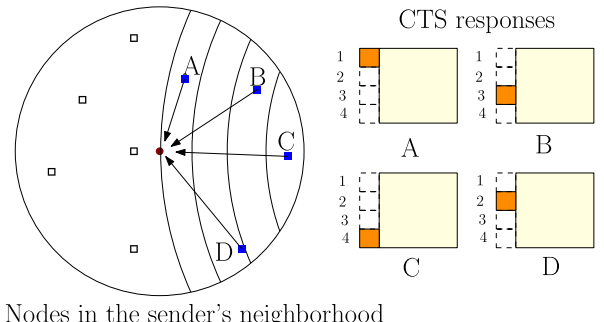

Fig. 1. The sender transmits a RTS message. The positive progress area (PPA) is sliced into four forwarding zones in this simple example. The CTS message contains a special OFDM response symbol. Each forwarding zone maps into a specific subcarrier. Candidate relaying node $\mathrm{C}$ will illuminate the 4th subcarrier since it offers the best positive progress towards the destination.

7) The candidate relaying node which has illuminated that subcarrier will receive the packet. All other nodes will go back to idle state.

There is an important consideration here. This is related to the case of two candidate relaying nodes having the more or less the same forwarding attributes, and thus selecting the same subcarrier index. In classical beaconless geo-routing, this would have mandated the design of a collision-resolution mechanism. The probability of such a situation was derived neatly in [4]. It can be straightforwardly shown that this probability is negligibly small for FFT sizes greater than 32 . As a matter of fact, we argue that there is no need for a collision-resolution mechanism in our case here. If two or more nodes happen to forward the packet concurrently, their transmissions can be simply regarded as artificial multipath. As such, the packet can still be received intact by the nodes of the next hop. The cyclic prefix in the $802.15 .4 \mathrm{~g}$ standard is $24 \mu \mathrm{s}$. This is in fact the amount of delay spread a receiver can handle. The excess path length corresponding to $24 \mu \mathrm{s}$ of delay spread is as high as $7.2 \mathrm{~km}$. By all means, this is much larger than the separation between two candidate relaying nodes.

\section{Performance Evaluation}

We have simulated the end-to-end energy performance of the optimized geo-routing protocol against RPL. A total of 6000, 8000, and 10000 smart meters respectively were distributed according to a Poisson Point Process (PPP) over an area of $1 \times 1 \mathrm{~km}$. This corresponds to a typical dense residential area. Performance was studied in terms of the distance from the smart meter to the sink. We have embarked on an application with a moderate traffic intensity such as Automated Demand Response (ADR) [5]. We have followed the strategy of rebuilding the neighbor list every time a message is exchanged between two neighbors as described in [6]. In this example, we have assumed that forwarding in the geo-routing protocol is done solely on position-based criteria. The average reference communication range is 100 meters.

Results are depicted in Figure 2. In the case of RPL, it is worthwhile noting that the overhead induced by neighbor discovery messages and link metric updates accumulates as the packet traverses the network towards the sink. This drives RPL to consume more energy compared to the optimized

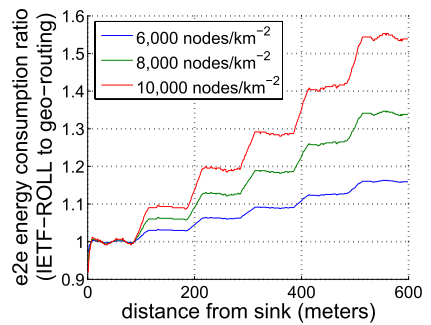

Fig. 2. Ratio of energy consumed in IETF-ROLL with respect to optimized beaconless geo-routing as function of distance from sink.

TABLE I

QUALITATIVE COMPARISON BETWEEN IETF-RPL AND OPTIMIZED GEO-RoutING

\begin{tabular}{|l|l|l|}
\hline & IETF-RPL & optimized geo-routing \\
\hline \hline Energy efficiency & $\begin{array}{l}\text { energy is consumed } \\
\text { in neighbor discovery } \\
\text { and updating link metrics }\end{array}$ & $\begin{array}{l}\text { Beaconless by design, } \\
\text { minimum transactions } \\
\text { per hop }\end{array}$ \\
\hline $\begin{array}{l}\text { Resilience to } \\
\text { topological } \\
\text { changes }\end{array}$ & $\begin{array}{l}\text { Fairly resilient, but } \\
\text { should be validated for } \\
\text { deep random } \\
\text { sleeping schedules }\end{array}$ & $\begin{array}{l}\text { Highly resilient since } \\
\text { contention takes place } \\
\text { on hop-by-hop basis }\end{array}$ \\
\hline Scalability & Needs further validation & $\begin{array}{l}\text { Highly scalable } \\
\text { (reduced MAC and } \\
\text { routing overhead) }\end{array}$ \\
\hline
\end{tabular}

geo-routing protocol. Other favorable features of the proposed optimized geo-routing protocol include scalability and resilience to topological changes (Table I).

\section{CONCLUSION}

In this letter, we have introduced a simple PHY-based method aimed at minimizing the forwarding delay in beaconless geo-routing protocols. The method can be applied in conjunction with the MR-OFDM specification of the IEEE 802.15.4g standard for Smart Utility Networks. The performance enhancement obtained through this PHY-based method makes the optimized geo-routing protocol a strong candidate for a layer-2 routing solution in SUNs.

\section{REFERENCES}

[1] Low-Rate Wireless Personal Area Networks (LR-WPANs) Amendment 3, Physical Layer (PHY) Specifications for Low- Data-Rate, Wireless, Smart Metering Utility Networks, IEEE Standard 15.4, 2012.

[2] T. Winter, P. Thubert, A. Brandt, T. Clausen, J. Hui, R. Kelsey, P. Levis, K. Pister, R. Struik, and J. P. Vasseur. (2012). RPL: IPv6 Routing Protocol for Low power and Lossy Networks, draft-ietf-rollrpl-19 [Online]. Available: http://tools.ietf.org/html/draft-ietf-roll-rpl-19

[3] J. Sanchez, P. Ruiz, and R. Marin-Perez, "Beacon-less geographic routing made practical: Challenges, design guidelines, and protocols," IEEE Commmun. Mag., vol. 47, no. 8, pp. 85-91, Aug. 2009.

[4] M. Zorzi and R. Rao, "Geographic random forwarding (GeRaF) for ad hoc and sensor networks: Energy and latency performance," IEEE Trans. Mobile Comput., vol. 2, no. 4, pp. 349-365, Oct. 2003.

[5] A. Patel, J. Aparicio, N. Tas, M. Loiacono, and J. Rosca, "Assessing communications technology options for smart grid applications," in Proc. IEEE Int. Conf. Smart Grid Commun., Oct. 2011, pp. 126-131.

[6] T. Watteyne, Kris K. Pister, D. Barthel, M. Dohler, and I. AugeBlum, "Implementation of gradient routing in wireless sensor networks," in Proc. IEEE Global Telecommun. Conf., Nov./Dec. 2009, pp. 1-6. 